\title{
Renal function deterioration in adult patients with type-2 diabetes
}

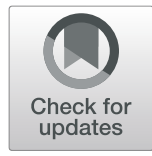

Peter Bramlage ${ }^{1^{*}}$ (D), Stefanie Lanzinger ${ }^{2,3}$, Eva Hess ${ }^{4}$, Simon Fahrner ${ }^{5}$, Christoph H. J. Heyer ${ }^{6}$, Mathias Friebe ${ }^{7}$, Ivo Buschmann ${ }^{8}$, Thomas Danne ${ }^{9}$, Reinhard W. Holl ${ }^{2,3+}$ and Jochen Seufert ${ }^{10+}$

\begin{abstract}
Background: To explore, in a large group of patients with type-2 diabetes (T2DM), renal function decline in terms of the slope of the estimated glomerular filtration rate (eGFR) over time, and to find out how classical risk factors, such as the presence of hypertension, dyslipidemia and microalbuminuria, affect the renal function.

Methods: The analysis included 32,492 adult T2DM patients from the DIVE/DPV registries who had serial eGFR determinations and information on the presence of microalbuminuria, hypertension and dyslipidemia available.

Results: Patients had a mean age of 66.3 years, $52.6 \%$ were male with a mean BMI of $31.7 \mathrm{~kg} / \mathrm{m}^{2}$. The mean eGFR was $78.4 \pm 21.4 \mathrm{~mL} / \mathrm{min} / 1.73 \mathrm{~m}^{2}$. The results showed that the prevalence of renal function impairment understood as chronic kidney disease (CKD) is considerable (53.0\%) in a population of patients with T2DM and has a high incidence rate of $6.6 \%$ within a year. Serial determinations of the eGFR are, however, infrequent $(7.8 \%$ of all patients) and these patients are characterised by the presence of a high-risk profile for CKD, such as hypertension (88.1\%) and dyslipidemia (66.1\%). Over a three-year time period, 30.9\% of the patients had an eGFR slope of -12 $\mathrm{mL} / \mathrm{min} / 1.73 \mathrm{~m}^{2}$ or more; and more than a doubled proportion of patients with an eGFR $<30 \mathrm{~mL} / \mathrm{min} / 1.73 \mathrm{~m}^{2}(3.8 \%$ vs. $1.8 \% ; p<0.001)$. Hypertension and albuminuria contributed to renal function decline while dyslipidemia did not negatively affect the slope.

Conclusion: CKD is highly prevalent in patients with T2DM. Serial surveillance of the glomerular filtration rate is, however, not established in clinical practice, which would be necessary as indicated by a doubling of patients with an eGFR $<30 \mathrm{~mL} / \mathrm{min} / 1.73 \mathrm{~m}^{2}$ within 3 years. Moreover, the use of renin-angiotensin blocking agents was low, pointing at considerable room for improvement. Taken together we conclude that a closer surveillance of patients with diabetes based on the presence of further risk factors is mandatory combined with a mandatory prescription of RAS blocking agents once microalbuminuria and / or renal function deterioration develops.
\end{abstract}

Keywords: Type 2 diabetes, Chronic kidney disease, eGFR slope, Hypertension, Dyslipidemia

\section{Background}

Diabetes is the leading risk factor for the development of renal impairment and end-stage renal disease [1]. Irrespective of a potential causal relationship, chronic kidney disease (CKD), defined as an eGFR $<60 \mathrm{~mL} / \mathrm{min} / 1.73 \mathrm{~m}^{2}$

\footnotetext{
* Correspondence: peter.bramlage@ippmed.de

${ }^{+}$Reinhard W. Holl and Jochen Seufert shared senior authorship

${ }^{1}$ Institute for Pharmacology and Preventive Medicine, Bahnhofstrasse 20, 49661 Cloppenburg, Germany

Full list of author information is available at the end of the article
}

OR an eGFR $\geq 60 \mathrm{~mL} / \mathrm{min} / 1.73 \mathrm{~m}^{2}$ together with albuminuria $(\geq 30 \mathrm{mg} / \mathrm{g}$ ), affects approximately $50 \%$ of the patients with type 2 diabetes mellitus (T2DM) [2, 3].

CKD is usually regarded as progressive and may eventually lead to end-stage renal disease (ESRD)/kidney failure. Although risk management strategies, including blood glucose control, have resulted in a decline of cardiovascular sequelae, the frequency of ESRD in patients with diabetes remains virtually unchanged $[4,5]$. A

(c) The Author(s). 2020 Open Access This article is licensed under a Creative Commons Attribution 4.0 International License, which permits use, sharing, adaptation, distribution and reproduction in any medium or format, as long as you give appropriate credit to the original author(s) and the source, provide a link to the Creative Commons licence, and indicate if changes were made. The images or other third party material in this article are included in the article's Creative Commons licence, unless indicated otherwise in a credit line to the material. If material is not included in the article's Creative Commons licence and your intended use is not permitted by statutory regulation or exceeds the permitted use, you will need to obtain permission directly from the copyright holder. To view a copy of this licence, visit http://creativecommons.org/licenses/by/4.0/ The Creative Commons Public Domain Dedication waiver (http://creativecommons.org/publicdomain/zero/1.0/) applies to the data made available in this article, unless otherwise stated in a credit line to the data. 
deeper understanding of the disease history and progression along with the development of new treatment strategies is mandatory to cope with the burden of ESRD worldwide [6].

We aimed to explore, in a large group of patients with T2DM, determinants of renal function decline, through assessment of the estimated glomerular filtration rate (eGFR) slope over time. Furthermore, we wanted to find out how classical risk factors, such as the presence of hypertension, dyslipidemia and microalbuminuria, would affect the further course and outcomes of T2DM patients in terms of their renal function.

\section{Methods}

\section{Study design and data sources}

This analysis used combined data from the DPV and DIVE registries $[7,8]$. Their design has been described previously. In short, the DPV initiative collects data on patients with diabetes mellitus from centers predominantly located in Germany [8,9]. Data are collected every 6 months using specific DPV software and the anonymized data are sent to the University of Ulm for aggregation into the database. The DPV initiative, which was established in 1995, was approved by the ethics committee of the University of Ulm, and data collection was approved by local review boards.

The DIVE registry was established in 2011 [2, 7, 10]. Consecutive patients with diabetes mellitus, regardless of their disease stage, were enrolled from centers across Germany, and continue to be followed up. Data are entered into an online database, which also uses the DPV software. The protocol was approved by the ethics committee of the Medical School of Hannover, and all patients included in the DIVE registry provided written informed consent.

Patients were sampled in March 2019 and included in the current analysis if they had T2DM, were at least 18 years old, initially registered between 2000 and 2017, and had an eGFR value calculated according to the Chronic Kidney Disease Epidemiology Collaboration (CKD-EPI) [11]. At least five eGFR measurements over a period of 3 years had to be available per patient.

\section{Documentation}

For each patient, where data on eGFR was available, we aggregated data per patient for the first year with eGFR measurement (baseline) up to 3 years follow-up. CKD was defined as eGFR $<60 \mathrm{~mL} / \mathrm{min} / 1.73 \mathrm{~m}^{2}$ OR an eGFR $\geq 60 \mathrm{~mL} / \mathrm{min} / 1.73 \mathrm{~m}^{2}$ and albuminuria $(\geq 30 \mathrm{mg} / \mathrm{g}$ ) [12, 13]. Hypertension was defined as blood pressure (BP) levels above $140 \mathrm{mmHg}$ systolic (SBP) or $90 \mathrm{mmHg}$ diastolic (DBP) or the receipt of antihypertensive drugs. Dyslipidemia was defined as an LDL-C cholesterol of $\geq 100 \mathrm{mg} / \mathrm{dL}$ without further risk factors and $\geq 70 \mathrm{mg} / \mathrm{dL}$ in patients with cardiovascular disease (CVD) or CKD or the receipt of lipid lowering drug treatment [14].

\section{Statistics}

Categorical variables are presented as percentages. Continuous variables are presented as medians with first and third quartiles (Q1, Q3). Unadjusted comparisons were conducted using a Chi-squared or Kruskal-Wallis test. A $p$-value $<0.05$ was considered statistically significant. The false discovery rate method was used to correct $p$ values for multiple testing.

eGFR-Slopes over the 3 years follow-up were estimated using a mixed linear regression model with a random participant intercept. eGFR-slopes were categorized into greater than $(>) 12$ (indicating improvement), 0 up to 12 , 0 down to -12 and smaller than $(<)-12$ (indicating worsening). We used multivariable logistic regression models to analyze the association between eGFR-slope categories and albuminuria, hypertension and dyslipidemia. Models were adjusted for age, sex, diabetes duration and BMI. As a sensitivity analysis models were additionally adjusted for ACE-inhibitor (ACEi) and angiotensin receptor blocker (ABR) use. We also conducted analyses stratified by comorbidity. Statistical analysis was performed using SAS version 9.4.

\section{Results}

The database included 413,239 adult patients with T2DM. For 237,538 patients, information on eGFR determinations and the level of albuminuria was available allowing the grouping of these patients into different CKD stages (Fig. 1). Of these patients, 91,411 had an eGFR of $1<60 \mathrm{~mL} / \mathrm{min} / 1.73 \mathrm{~m}^{2}$, and $34,586 \mathrm{had}$ an eGFR of $\geq 60 \mathrm{~mL} / \mathrm{min} / 1.73 \mathrm{~m}^{2}$ but with an albuminuria of at least $30 \mathrm{mg} / \mathrm{g}$. As such, the prevalence of CKD was $53.0 \%$. This value was slightly lower than in a prior analysis of the same dataset sampled one year earlier [2]. For $6.6 \%(27,201$ of 413,239$)$ of the patients, CKD was observed for the first time within in the last year of documentation (Fig. 2).

\section{Baseline characteristics}

Of the 413,239 patients, 32,492 patients had at least five eGFR determinations within a time frame of three years and all variables available for the subsequent analyses. These patients had a mean age of 66.3 years and $52.6 \%$ were male with a mean BMI of $31.7 \mathrm{~kg} / \mathrm{m}^{2}$ (Table 1). T2DM was diagnosed a mean of 11.3 years previously. The majority of patients were treated with metformin (56.7\%), followed by insulin (45.8\%), sulfonylurea (19.4\%) and DPP-4 inhibitors (16.7\%). Hypertension was documented for $88.1 \%$ of the patients and $66.1 \%$ had dyslipidemia. Patients in the analysis set $(n=32,492)$ differed from the total cohort of T2DM patients $(n=413,239)$ 


\begin{tabular}{|c|c|c|c|c|c|c|}
\hline \multicolumn{4}{|c|}{ Prevalence $(\mathrm{n}=237,528)$} & Normal & Microalbuminuria & Macroalbuminuria \\
\hline \multirow{6}{*}{ 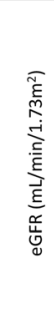 } & 1 & Normal & $\geq 90$ & $42,285(17.8 \%)$ & 11,995 (5.1\%) & $1,438(0.6 \%)$ \\
\hline & 2 & Mild limitation & $60-89$ & $69,246(29.2 \%)$ & $18,372(7.7 \%)$ & $2,781(1.2 \%)$ \\
\hline & $3 a$ & Mild-to-moderate & $45-59$ & 28,736 (12.1) & $8,428(3.6 \%)$ & 1,985 (0.8\%) \\
\hline & $3 \mathrm{~b}$ & Moderate-to-severe & $30-44$ & $20,981(8.8 \%)$ & $6,979(2.9 \%)$ & $2,083(0.9 \%)$ \\
\hline & 4 & Severe limitation & $15-29$ & $10,462(4.4 \%)$ & $3,912(1.7 \%)$ & 2,173 (0.9\%) \\
\hline & 5 & Kidney failure & $<15$ & $2,091(0.9 \%)$ & $866(0.4 \%)$ & 2,715 (1.1\%) \\
\hline
\end{tabular}

Fig. 1 Chronic Kidney Disease prevalence by eGFR and albuminuria (based on [2, 12]). Green, low risk (if no other markers of kidney disease, no (KD); yellow, moderately increased risk; orange, high risk; red, very high risk

with a substantially higher use of metformin $(56.7 \%$ vs. $35.7 \%)$ and sulfonylureas (19.4\% vs. $10.6 \%)$, by a higher rate of hypertension ( $88.1 \%$ vs. $74.7 \%)$, and higher ACEi/ ARB use (59.4\% vs. $39.5 \%)$ (Table 1$)$.

\section{Renal function/eGFR slope}

In terms of their renal function, $63.2 \%$ of the patients had macroalbuminuria, $34.0 \%$ had microalbuminuria and $2.8 \%$ macroalbuminuria (any albuminuria $36.8 \%$ ). At a mean eGFR of $78.4 \mathrm{~mL} / \mathrm{min} / 1.73 \mathrm{~m}^{2}, 1.8 \%$ of all patients had an eGFR of $<30,18.4 \%$ of between 30 and $<$ 60 , and $78.7 \%$ of $\geq 60 \mathrm{~mL} / \mathrm{min} / 1.73 \mathrm{~m}^{2}$ (Table 2). Over a three-year time period, renal function deteriorated with an increase in the rate of albuminuria $(+4.1 \%)$ and a decline of the eGFR with more than doubling of patients with an eGFR $<30$ ( $3.8 \%$ vs. $1.8 \%$; $p<0.001)$.

The eGFR slope, defined as a decrease of the eGFR over time, was highly variable (Table 3). Overall 54.3\% patients had a decline of their eGFR within 3 years, with $30.9 \%$ having a decline of more than $-12 \mathrm{~mL} / \mathrm{min} /$ $1.73 \mathrm{~m}^{2}$, and $23.4 \%$ a decline of between 0 and $-12 \mathrm{~mL} /$ $\mathrm{min} / 1.73 \mathrm{~m}^{2}$. Conversely, $45.7 \%$ of patients had a stable or increased eGFR.

Patients with a decline in renal function (slope of 12 or more; Table 3) had a compromised eGFR at baseline $\left(48.5 \mathrm{~mL} / \mathrm{min} / 1.73 \mathrm{~m}^{2}\right)$, while patients with an increase in the eGFR were those with a normal renal function at baseline (mean eGFR $99.8 \mathrm{~mL} / \mathrm{min} / 1.73 \mathrm{~m}^{2}$ in those with an increase of $>12 ; 83.5 \mathrm{~mL} / \mathrm{min} / 1.73 \mathrm{~m}^{2}$ in those with an increase between 0 and 12). Furthermore, patients with a slope of more than -12 were older (74.1 vs. 56.9 years), more often female (56.1 vs. $42.7 \%$ ), with a longer diabetes duration (14.0 vs. 9.1 years), an increased rate of hypertension (91.8 vs. 83.6\%), and had a higher rate of micro- ( 50.9 vs. $42.3 \%)$ and even more so macroalbuminuria (7.7 vs. $1.7 \%$ ) than patients with an increased eGFR $(>12)$. This trend was consistent through all slope categories. Interestingly, rates of dyslipidemia were lower in those patients with a steep renal function decline.

\section{Albuminuria, hypertension and dyslipidemia}

Albuminuria was indicative of a steeper slope of the eGFR. The prevalence of microalbuminuria was $50.9 \%$ in patients with a slope of more than $-12 \mathrm{~mL} / \mathrm{min} / 1.73 \mathrm{~m}^{2}$ decline while it was in the order of $41 \%$ in patients with an eGFR change from -12 to positive values (Table 4). This pattern persisted even after multivariable adjustment for age, sex, diabetes duration, BMI and ACEi / ARB use, with a $p$-value $<0.001$ for the difference across eGFR slope categories.

\begin{tabular}{|c|l|l|l|l|l|l|}
\hline \multicolumn{2}{|l|}{ Incidence $(\mathrm{n}=17,956)^{*}$} & $\begin{array}{l}\text { Normal } \\
<30 \mathrm{mg} / \mathrm{g}\end{array}$ & $\begin{array}{l}\text { Microalbuminuria } \\
30-300 \mathrm{mg} / \mathrm{g}\end{array}$ & $\begin{array}{l}\text { Macroalbuminuria } \\
>300 \mathrm{mg} / \mathrm{g}\end{array}$ \\
\hline & 1 & Normal & 290 & $219(1.2 \%)$ & $1,939(10.8 \%)$ & $299(1.7 \%)$ \\
\hline
\end{tabular}

Fig. 2 Chronic Kidney Disease incidence by eGFR and albuminuria (based on [2, 12]). Green, low risk (if no other markers of kidney disease, no (KD); yellow, moderately increased risk; orange, high risk; red, very high risk. *There were 27,201 patients with incident CKD during one year. For 9245 of these patients we were not able to group them into risk classes 
Table 1 Patient characteristics $(N=32,492)$

\begin{tabular}{|c|c|c|}
\hline & $\begin{array}{l}\text { All patients with T2DM }(n=413,239) \\
\text { mean } \pm \text { SD or } \%\end{array}$ & $\begin{array}{l}\text { Subgroup }(n=32,492) \\
\text { mean } \pm \text { SD or } \%\end{array}$ \\
\hline Age, years & $68.2 \pm 12.9$ & $66.3 \pm 11.4$ \\
\hline Male gender, \% & 52.8 & 52.6 \\
\hline Body mass index, $\mathrm{kg} / \mathrm{m}^{2}$ & $31.0 \pm 6.7$ & $31.7 \pm 6.2$ \\
\hline Diabetes duration, years & $10.5 \pm 9.2$ & $11.3 \pm 8.5$ \\
\hline $\mathrm{HbA} 1 \mathrm{c}, \%$ & $7.6 \pm 1.9$ & $7.0 \pm 1.0$ \\
\hline \multicolumn{3}{|l|}{ Antidiabetic drug treatment } \\
\hline Insulin, \% & 47.1 & 45.8 \\
\hline Metformin, \% & 35.7 & 56.7 \\
\hline DPP4-inhibitors, \% & 13.8 & 16.7 \\
\hline Sulfonylurea, \% & 10.6 & 19.4 \\
\hline Glinides, \% & 3.2 & 7.5 \\
\hline Acarbose, $\%$ & 1.1 & 2.1 \\
\hline Sensitizers, \% & 1.0 & 4.5 \\
\hline GLP-1 analogues, \% & 2.9 & 6.6 \\
\hline SGLT-2 inhibitors, \% & 2.5 & 4.2 \\
\hline Hypertension, \% & 74.7 & 88.1 \\
\hline Syst. blood pressure, $\mathrm{mmHg}$ & $135.4 \pm 18.3$ & $135.5 \pm 12.5$ \\
\hline Diast. blood pressure, $\mathrm{mmHg}$ & $77.4 \pm 10.6$ & $78.6 \pm 7.3$ \\
\hline Antihypertensive drug treatment, \% & 52.1 & 67.0 \\
\hline ACEi, \% & 28.2 & 37.8 \\
\hline ARBs, $\%$ & 11.3 & 21.6 \\
\hline Betablockers, \% & 28.4 & 35.1 \\
\hline Calcium channel blockers, \% & 14.7 & 23.7 \\
\hline Diuretics, \% & 28.7 & 31.8 \\
\hline Dyslipidemia, \% & 47.6 & 66.1 \\
\hline \multicolumn{3}{|l|}{ Kidney parameters } \\
\hline eGFR, $\mathrm{mL} / \mathrm{min} / 1.73 \mathrm{~m}^{2}$ & $68.2 \pm 26.5$ & $76.7 \pm 21.7$ \\
\hline Serum potassium, mmol/L & $4.3 \pm 0.6$ & $4.4 \pm 0.5$ \\
\hline \multicolumn{3}{|l|}{ Comorbidity at baseline } \\
\hline Myocardial infarction, \% & 8.1 & 9.7 \\
\hline Stroke, \% & 7.3 & 8.0 \\
\hline Heart failure, \% & 5.7 & 9.2 \\
\hline Peripheral artery disease, $\%$ & 16.3 & 32.8 \\
\hline Major amputation, \% & 0.9 & 0.8 \\
\hline Minor amputation, \% & 2.2 & 1.9 \\
\hline Diabetic neuropathy, \% & 43.6 & 69.5 \\
\hline Diabetic foot syndrome, \% & 11.6 & 25.1 \\
\hline Diabetic retinopathy, \% & 4.8 & 13.5 \\
\hline
\end{tabular}

Legend: DPP dipeptidyl peptidase-4, eGFR estimated glomerular filtration rate, GLP-1 glucagon-like peptide-1, HDL high-density lipoprotein, $L D L$ low-density lipoprotein, SGLT-2 sodium-glucose transport protein-2

The presence of hypertension also adds risk to a decline of renal function. At an overall hypertension prevalence of $88.1 \%$, hypertension rates were $91.8 \%$ in those with an eGFR slope of $>12$. This pattern is slightly alleviated, but still retained if numbers are adjusted for age, sex, duration and BMI with a p-value of 0.002. ACEi/ARB use adjustment was not performed as the use of antihypertensive drugs interferes with the definition of hypertension. 
Table 2 Kidney parameters at baseline and throughout a 3-year follow-up ( $N=32,492$ at baseline)

\begin{tabular}{|c|c|c|c|c|c|}
\hline & Baseline & at 1 year & at 2 years & at 3 years & $\Delta 3$ years vs. baseline \\
\hline \multicolumn{6}{|l|}{ Albuminuria } \\
\hline Normoalbuminuria ${ }^{a}, \%$ & 63.2 & 60.2 & 58.8 & 59.1 & -4.1 \\
\hline Microalbuminuria, \% & 34.0 & 36.8 & 37.9 & 37.2 & +3.2 \\
\hline Macroalbuminuria, \% & 2.8 & 3.0 & 3.3 & 3.7 & +0.9 \\
\hline $\mathrm{eGFR}, \mathrm{ml} / \mathrm{min} / 1.73 \mathrm{~m}^{2}$ & $78.4 \pm 21.4$ & $77.6 \pm 21.8$ & $76.0 \pm 22.2$ & $74.5 \pm 23.1$ & -3.9 \\
\hline eGFR $\geq 90, \%$ & 32.9 & 32.2 & 29.7 & 28.4 & -4.5 \\
\hline eGFR 60 to $<90, \%$ & 45.8 & 46.4 & 46.4 & 45.2 & -0.6 \\
\hline eGFR 45 to $<60, \%$ & 13.0 & 12.9 & 13.9 & 14.6 & +1.6 \\
\hline eGFR 30 to $<45, \%$ & 5.4 & 6.3 & 7.1 & 8.0 & +2.6 \\
\hline eGFR 15 to $<30, \%$ & 1.5 & 1.8 & 2.3 & 3.1 & +1.6 \\
\hline eGFR < 15, \% & 0.3 & 0.5 & 0.5 & 0.7 & +0.4 \\
\hline \multicolumn{6}{|l|}{ Chronic kidney disease $^{b}$} \\
\hline Low risk & 33.0 & 32.2 & 29.7 & 28.4 & -4.6 \\
\hline Moderate risk & 46.8 & 46.4 & 46.4 & 45.2 & -1.6 \\
\hline High risk & 18.4 & 19.2 & 21.0 & 22.6 & +4.2 \\
\hline Very high risk & 1.8 & 2.2 & 2.9 & 3.8 & +2.0 \\
\hline
\end{tabular}

Dyslipidemia, defined as an LDL-C of at least $100 \mathrm{mg} /$ $\mathrm{dL}$ or at least $70 \mathrm{mg} / \mathrm{dL}$ in the presence of $\mathrm{CVD} / \mathrm{CKD}$, was noted in $66.1 \%$ of patients. Rates were lower in patients with a steep eGFR slope ( -12 or smaller) and higher in those with a retained eGFR. This pattern persisted after adjustment for age, sex, diabetes duration, BMI and ACEi / ARB use $(p<0.001)$.

In a composite analysis the presence of microalbuminuria $(-1.51 ; 95 \% \mathrm{CI}-1.81$ to 1.22$)$ and the absence of dyslipidemia $(-3.82 ; 95 \%$ CI -4.20 to 3.45$)$ had the highest impact on the progression of an eGFR decline. This was up and beyond the effects of age, gender, diabetes duration and BMI.

\section{Discussion}

The results of the present analysis show that the prevalence of renal function impairment understood as CKD is considerable and has a high incidence rate within a year. Serial determinations of the glomerular filtration rate are, however, infrequent and these patients are characterised by the presence of a high-risk profile for CKD, such as hypertension and dyslipidemia. Moreover, the use of renin-angiotensin blocking agents were low, pointed at considerable room for improvement. Over a three-year time period, one-third of these patients had an eGFR slope of -12 or more and a more than doubled proportion of patients with an eGFR $<30 \mathrm{~mL} / \mathrm{min} / 1.73$ $\mathrm{m}^{2}$. Hypertension and albuminuria contributed to renal function decline while dyslipidemia did not negatively affect the slope.

\section{Prevalence and incidence of CKD}

We based our definition of CKD on the decline of renal function (eGFR $<60 \mathrm{~mL} / \mathrm{min} / 1.73 \mathrm{~m}^{2}$ ) and the presence of urinary albumin. As previously published, our cohort of T2DM patients is characterized by a CKD prevalence in the order of $50.0 \%$ [2], based on data obtained up until March 2018. While the rate of 53.0\% in the current sample as of March 2019 may be numerically higher, it is not very likely that it represents a more general trend. The order, however, is consistent with other publications when different definitions and patient populations are considered. Gonzalez-Perez et al. reported that 29,104 out of 109,365 patients with newly diagnosed T2DM (26.6\%) already had CKD with an incidence rate of 5.5 per 100 years [15]. Zelnick et al. reported, for patients with diabetes, a prevalence of $25 \%$ [16]. While the former reported rates in patients with newly diagnosed diabetes, the latter excluded those with albuminuria at a GFR of $>60 \mathrm{~mL} / \mathrm{min} / 1.73 \mathrm{~m}^{2}$. As such, we believe that a prevalence rate in the order of $50 \%$ is a good estimate of the true prevalence in T2DM, which is reconfirmed by others [17].

\section{Renal function decline}

We would assume that, in patients with T2DM, there is a linear decline in renal function over time eventually leading to end-stage renal disease and dialysis in a subset of patients. The GFR decline in T2DM patients is almost twice as high as in patients without diabetes [18]. This is even more true with an ageing population as patients 
Table 3 Patient characteristics $(N=32,492)$

\begin{tabular}{|c|c|c|c|c|}
\hline & $\begin{array}{l}\text { eGFR-increase }{ }^{a} \\
>12 \\
(27.1 \% \text { of pts) }\end{array}$ & $\begin{array}{l}\text { eGFR-increase } \\
0 \text { up to }+12 \\
\text { (18.6\% of pts) }\end{array}$ & $\begin{array}{l}\text { eGFR-slope }{ }^{a} \\
0 \text { down to }-12 \\
\text { ( } 23.4 \% \text { of pts) }\end{array}$ & $\begin{array}{l}\text { eGFR-slope }{ }^{a} \\
-12 \text { or smaller } \\
\text { (30.9\% of pts) }\end{array}$ \\
\hline Age, years & $56.9 \pm 10.2$ & $66.9 \pm 9.0$ & $69.8 \pm 8.5$ & $74.1 \pm 8.2$ \\
\hline Male gender, \% & 57.3 & 57.5 & 51.2 & 43.9 \\
\hline Body mass index, $\mathrm{kg} / \mathrm{m}^{2}$ & $32.5 \pm 6.7$ & $31.0 \pm 5.8$ & $31.2 \pm 5.9$ & $31.7 \pm 6.0$ \\
\hline Diabetes duration, years & $9.1 \pm 6.9$ & $10.8 \pm 8.0$ & $11.7 \pm 8.7$ & $14.0 \pm 9.5$ \\
\hline $\mathrm{HbA} 1 \mathrm{c}, \%$ & $7.0 \pm 1.1$ & $6.9 \pm 0.9$ & $6.9 \pm 0.9$ & $7.0 \pm 0.9$ \\
\hline \multicolumn{5}{|l|}{ Antidiabetic drug treatment } \\
\hline Insulin, \% & 41.8 & 41.8 & 44.6 & 54.6 \\
\hline Metformin, \% & 68.6 & 61.8 & 58.4 & 37.5 \\
\hline DPP4-inhibitors, \% & 17.1 & 14.1 & 15.9 & 19.1 \\
\hline Sulfonylurea, \% & 18.1 & 20.6 & 20.3 & 19.3 \\
\hline Glinides, \% & 6.4 & 6.8 & 7.0 & 9.7 \\
\hline Acarbose, \% & 1.7 & 2.1 & 2.1 & 2.5 \\
\hline Sensitizers, \% & 4.8 & 4.6 & 4.2 & 4.3 \\
\hline GLP-1 analogues, \% & 11.2 & 5.8 & 4.8 & 3.3 \\
\hline SGLT-2 inhibitors, \% & 7.3 & 3.6 & 3.0 & 1.9 \\
\hline Hypertension, \% & 83.6 & 88.0 & 89.9 & 91.8 \\
\hline Syst. blood pressure, mmHg & $134.9 \pm 12.4$ & $136.1 \pm 12.3$ & $135.8 \pm 12.4$ & $135.5 \pm 12.7$ \\
\hline Diast. blood pressure, mmHg & $80.9 \pm 7.1$ & $78.9 \pm 6.9$ & $78.1 \pm 7.0$ & $76.2 \pm 7.3$ \\
\hline Antihypertensive drug treatment, \% & 60.0 & 66.5 & 69.5 & 73.9 \\
\hline ACEi, \% & 35.3 & 37.1 & 38.4 & 40.7 \\
\hline ARBs, \% & 18.0 & 20.6 & 22.1 & 26.2 \\
\hline Betablockers, \% & 26.4 & 32.4 & 37.8 & 45.5 \\
\hline Calcium channel blockers, \% & 18.5 & 22.5 & 24.1 & 30.5 \\
\hline Diuretics, \% & 19.6 & 26.9 & 32.7 & 49.5 \\
\hline Dyslipidemia, \% & 68.7 & 68.2 & 69.2 & 59.1 \\
\hline \multicolumn{5}{|l|}{ Kidney parameters } \\
\hline $\mathrm{eGFR}, \mathrm{mL} / \mathrm{min} / 1.73 \mathrm{~m}^{2}$ & $99.8 \pm 8.6$ & $83.5 \pm 4.3$ & $70.7 \pm 4.5$ & $48.5 \pm 12.3$ \\
\hline Serum potassium, mmol/L & $4.4 \pm 0.4$ & $4.4 \pm 0.4$ & $4.4 \pm 0.4$ & $4.4 \pm 0.5$ \\
\hline \multicolumn{5}{|l|}{ Albuminuria } \\
\hline Microalbuminuria, \% & 42.3 & 40.4 & 41.8 & 50.9 \\
\hline Macroalbuminuria, \% & 1.7 & 1.9 & 2.2 & 7.7 \\
\hline \multicolumn{5}{|l|}{ Comorbidity at baseline } \\
\hline Myocardial infarction, \% & 5.4 & 8.9 & 10.3 & 14.8 \\
\hline Stroke, \% & 3.9 & 7.7 & 8.8 & 12.6 \\
\hline Heart failure, $\%$ & 4.1 & 7.3 & 8.1 & 16.1 \\
\hline Peripheral artery disease, \% & 22.2 & 31.3 & 35.1 & 44.6 \\
\hline Major amputation, \% & 0.5 & 0.7 & 0.9 & 1.2 \\
\hline Minor amputation, \% & 0.9 & 1.4 & 1.9 & 3.4 \\
\hline Diabetic neuropathy, \% & 61.1 & 68.7 & 72.2 & 77.9 \\
\hline Diabetic foot syndrome, \% & 18.6 & 23.8 & 27.4 & 32.2 \\
\hline Diabetic retinopathy, \% & 9.6 & 11.6 & 14.3 & 19.1 \\
\hline
\end{tabular}


Table 4 Association between albuminuria, hypertension, dyslipidemia and GFL-slope categories

\begin{tabular}{|c|c|c|c|c|}
\hline & $\begin{array}{l}\text { Univariate } \\
\text { frequency }(95 \% \mathrm{Cl})\end{array}$ & $\begin{array}{l}\text { Model } 1 \\
\text { frequency }(95 \% \mathrm{Cl})\end{array}$ & $\begin{array}{l}\text { Model } 2 \\
\text { frequency }(95 \% \mathrm{Cl})\end{array}$ & $\boldsymbol{p}$-value Model 2 \\
\hline \multicolumn{5}{|l|}{ Microalbuminuria (\%) } \\
\hline eGFR-increase $^{a}>12$ & $42.3(41.3-43.4)$ & $42.9(41.7-44.1)$ & $42.8(41.6-44.0)$ & \multirow[t]{4}{*}{$<0.001$} \\
\hline eGFR-increase $^{a} 0$ up to +12 & $40.4(39.2-41.6)$ & $40.3(39.1-41.5)$ & $40.3(39.1-41.5)$ & \\
\hline eGFR-slope ${ }^{a} 0$ down to -12 & $41.8(40.5-43.2)$ & $41.4(40.1-42.8)$ & $41.3(40.0-42.7)$ & \\
\hline eGFR-slope ${ }^{a}-12$ or smaller & $50.9(49.7-52.0)$ & $49.4(48.2-50.7)$ & $49.1(47.9-50.4)$ & \\
\hline \multicolumn{5}{|l|}{ Hypertension (\%) } \\
\hline eGFR-increase ${ }^{a}>12$ & $83.6(82.9-84.4)$ & $88.4(87.7-89.1)$ & n.a. & \multirow[t]{4}{*}{$0.002^{b}$} \\
\hline eGFR-increase ${ }^{a} 0$ up to +12 & $88.0(87.3-88.8)$ & $89.0(88.2-89.7)$ & n.a. & \\
\hline eGFR-slope 0 down to -12 & $89.9(89.2-90.7)$ & 89.9 (89.0-90.6) & n.a. & \\
\hline eGFR-slope ${ }^{a}<-12$ or smaller & $91.8(91.3-92.4)$ & $90.4(89.7-91.1)$ & n.a. & \\
\hline \multicolumn{5}{|l|}{ Dyslipidemia (\%) } \\
\hline eGFR-increase ${ }^{a}>12$ & $68.7(67.7-69.6)$ & $70.7(69.6-71.7)$ & $72.4(71.3-73.4)$ & \multirow[t]{4}{*}{$<0.001$} \\
\hline eGFR-increase $\mathrm{e}^{\mathrm{a}} 0$ up to +12 & $68.2(67.1-69.2)$ & $68.2(67.1-69.3)$ & $69.9(68.8-71.0)$ & \\
\hline eGFR-slope ${ }^{a} 0$ down to -12 & $69.2(68.0-70.4)$ & $69.0(67.8-70.2)$ & $70.4(69.2-71.6)$ & \\
\hline eGFR-slope ${ }^{a}<-12$ or smaller & $59.1(58.1-60.2)$ & $58.9(57.7-60.0)$ & $58.7(57.5-60.0)$ & \\
\hline
\end{tabular}

Legend: ${ }^{a}$ Within a time span of 3 years; ${ }^{\mathrm{b}} \mathrm{p}$-value Model 1; Model 1 adjusted for age, sex, duration and BMl; Model 2 adjusted for model 1 variables plus ACEinhibitor use and/or ARB use

increasingly survive cardiovascular events and have sufficient time to develop renal disease [17]. The linearity of this decline has been challenged more recently with data showing a non-linear or even non-progression in patients with CKD [19]. While this research was performed in patients without diabetes, Weldegiorgis et al. suggested than non-linearity may be particularly frequent in those with diabetes [20]. These data are in full alignment with our own findings. The proportion of patients with an eGFR $<30 \mathrm{~mL} / \mathrm{min} / 1.73 \mathrm{~m}^{2}$ doubled within the observational period of 3 years in the subset of patients where the treating physician performed a closer surveillance of the renal function $(3.8 \%$ vs. $1.8 \% ; p<0.001)$. Overall, $30.9 \%$ of the patients had an eGFR slope of -12 or more which is consistent with the general renal function decline, but, on the other hand, a substantial proportion of patients also had a more or less stable decline or even eGFR increase which was mostly observed in those patients with a normal or just mildly impaired eGFR at baseline. This is potentially in agreement with the initial hyperfiltration observed in early renal function decline. While this may be influenced by the variability of eGFR determinations itself [21], it should also be regarded as a reflection of the non-linear decline of renal function in patients with diabetes [22].

\section{Renal function decline cofactors}

There is a considerable overlap between patients with reduced eGFR and those showing varying degrees of urinary albumin excretion. While there are patients in stage 3 CKD but with normoalbuminuria [23-25] (26.2\% in our population), there are also patients without or with only mild reductions in the eGFR, but showing varying levels of urinary albumin excretion $(14.6 \%$ in our cohort). The presence of albuminuria in patients with reduced GFR has been associated with progressive kidney disease [26] and confers additional risk [2, 12]. Consistent with this research, renal function decline in our dataset was pronounced in the presence of albuminuria with a faster deterioration in patients with macroalbuminuria than microalbuminuria, which is in line with recent meta-analyses [26, 27].

Hypertension prevalence was higher in patients with accelerated renal function decline in our dataset. It is a well-recognized risk factor and antihypertensive treatment, especially the use of ACEi or ARBs is considered to slow the eGFR decline. This was recently reconfirmed in an analysis of the Atherosclerosis Risk in Communities (ARIC) study [28]. Compared to normotension, hypertension status was associated with faster kidney function decline over 30-year follow-up in a general population cohort. This difference was attenuated among people using antihypertensive medications.

We were surprised by a lack of an association or even a reverse relationship between dyslipidemia and eGFR slope. We defined dyslipidemia as an LDL-C cholesterol of $\geq 100 \mathrm{mg} / \mathrm{dL}$ without further risk factors and $\geq 70 \mathrm{mg} /$ $\mathrm{dL}$ in patients with CVD or CKD or patients receiving lipid-lowering drug treatment. The definition resulted in higher dyslipidemia rates in those with CKD, but there was no increase in the eGFR slope seen. The results are difficult to interpret, as research on the relationship 
between dyslipidemia and GFR function decline is sparse. One of the few studies is a retrospective Japanese study in 4326 patients that shows an association of dyslipidemia with the deterioration of proteinuria and renal function. The authors found that neither total cholesterol nor LDL-C (but high triglyceride levels) were associated with renal function decline [29]. Moreover, it appears that lipid-lowering treatment is usually considered not to be associated with renal function decline, but is mandatory to ameliorate the adverse long-term cardiovascular outcomes [30]. Actually, in our own dataset we found comparable levels of total cholesterol and LDL-C, while triglycerides were higher in those with renal function decline.

\section{Guideline considerations}

Early detection and treatment of CKD may delay or prevent the development of end-stage kidney disease, morbidity, and mortality. Aiming at the improvement of early CKD detection, the Kidney Disease Outcomes Quality Initiative (K/DOQI) of the National Kidney Foundation published clinical practice guidelines recommending the use of estimating equations of GFR on the basis of serum creatinine determinations and Urinary-Albumin-Creatinine-Ratio (UACR) [12, 13]. The American Diabetes Association (ADA, 2020) [31] recommends spot urinary albumin-to-creatinine ratio, serum creatinine and estimated glomerular filtration rates evaluations at baseline and then annually. This approach was recently reinforced by the ESC in collaboration with the EASD (2020) [32]. Although there is no formal guidance from the American Society of Nephrology (ASN) they strongly advocate "regular screening for kidney disease regardless of risk factors" [33, 34], similar to a statement published by the National Kidney Foundation (NKF) and the Renal Physicians Association (RPA) [35].

Based on our own observations, more than $90 \%$ of patients with diabetes in Germany received no regular kidney disease screening. Patients that were screened were at increased risk, based on their patient profile as diabetic patients and had a higher prevalence of concomitant hypertension and microalbuminuria. While the adequacy of this approach deserves further investigation it appears that targeting at risk patients is a viable strategy to detect patients with kidney disease early. Australia, Canada, Japan, UK, and the USA have established such effective surveillance mechanisms for chronic kidney disease in an attempt to detect the disease early and improve outcomes [36-38]. A recent research project investigated the effects of a virtual CKD clinic (VC) in patients with CKD. It consisted of a nonface-to-face computer-assisted review of patient data and was associated with improved survival compared to standard care and a reduction in patients requiring emergency dialysis [39].

\section{Limitations}

The current registry analysis reflects real-world diagnostic and treatment patterns in a very large group of patients with T2DM, which is representative for patients treated in Germany. As such, it gives valuable insight up and beyond clinical trials into patient groups that were potentially never studied in clinical trials. We found that only $7.8 \%$ of the patients received serial eGFR determinations over a time frame of 3 years, which reflects clinical practice, but also defines a subset of patients where physicians felt particular attention was needed. It appears as if antiproteinuric, as well as antihypertensive, treatment provides benefit, while lipid-lowering drugs may not ameliorate the progression of kidney disease.

\section{Conclusions}

Chronic kidney disease is highly prevalent in a T2DM patient population. Serial surveillance of the glomerular filtration rate is, however, not routinely established in clinical practice, which would be necessary as indicated by a doubling of patients with an eGFR $<30 \mathrm{~mL} / \mathrm{min} /$ $1.73 \mathrm{~m}^{2}$ within 3 years. Moreover, the use of reninangiotensin blocking agents was low, pointing at considerable room for improvement. Taken together we conclude that a closer surveillance of patients with diabetes based on the presence of further risk factors is mandatory combined with a mandatory prescription of RAS blocking agents once microalbuminuria and / or renal function deterioration develops.

\section{Abbreviations}

ACEi: ACE-inhibitor; ARB: Angiotensin receptor blocker; BMI: Body mass index; BP: Blood pressure; Cl: Confidence Interval; CKD: Chronic kidney disease; CKD-EPI: Chronic Kidney Disease Epidemiology Collaboration;

CVD: Cardiovascular disease; DBP: Diastolic blood pressure; eGFR: Estimated glomerular filtration rate; ESRD: End-stage renal disease; GFR: Glomerular

filtration rate; LDL-C: Low density lipoprotein cholesterol; SBP: Systolic blood pressure; T2DM: Type 2 diabetes mellitus

\section{Acknowledgements}

We thank all participating centers of the DPV and DIVE initiatives,

\section{Authors' contributions}

$\mathrm{EH}, \mathrm{SF}, \mathrm{CHJH}, \mathrm{MF}$, and TD contributed to the data collection. PB, SL, IB, and RWH designed the analysis, drafted the manuscript and created Figs. SL and RWH were responsible for the statistical analyses. EH, SF, CHJH, MF, IB, TD,

$\mathrm{RWH}$, and JS contributed to the discussion and reviewed/edited the manuscript. RWH had full access to all the data in the study and takes responsibility for the integrity of the data and the accuracy of the data analysis. All authors approved the final manuscript to be submitted.

\section{Funding}

The DPV registry was supported by the European Foundation for the Study of Diabetes (EFSD). Further financial support was provided by the German Diabetes Society (DDG) and the German Centre for Diabetes Research (DZD). The DIVE registry received funding from Sanofi, AstraZeneca, Bayer, and Abbott. Funders were not involved in the analysis and interpretation of data, the writing of the report or the decision to submit the article for publication. 


\section{Availability of data and materials}

The datasets generated and analyzed during the current study are not publicly available due to data privacy but are available from the corresponding author on reasonable request.

\section{Ethics approval and consent to participate}

The DPV initiative, which was established in 1995, was approved by the ethics committee of the University of Ulm, and data collection was approved by local review boards.

The DIVE registry was established in Germany in 2011. The protocol was approved by the ethics committee of the Medical School of Hannover, and all patients included in the DIVE registry provided written informed consent.

\section{Consent for publication}

Not applicable.

\section{Competing interests}

JS and TD report grants and personal fees from Abbott, AstraZeneca, and Sanofi, outside the submitted work. PB reports to have received consultancy honoraria from Sanofi and Abbott. SL, IB, EH, SF, CHJH, MF, and RWH have no competing interests to disclose.

\section{Author details}

${ }^{1}$ Institute for Pharmacology and Preventive Medicine, Bahnhofstrasse 20, 49661 Cloppenburg, Germany. ${ }^{2}$ Institut für Epidemiologie und medizinische Biometrie, ZIBMT, Universität UIm, UIm, Germany. ${ }^{3}$ Deutsches Zentrum für Diabetesforschung e.V, München-Neuherberg, Germany. ${ }^{4}$ Diabetologische Schwerpunktpraxis Dres, Hess, Worms, Germany. ${ }^{5}$ Medizinische Klinik, SRH Klinik Sigmaringen, Pfullendorf, Germany. 'Diabetespraxis Viersen, Viersen, Germany. ${ }^{7}$ Evangelisches Krankenhaus, Oberhausen, Germany. ${ }^{8}$ Department of Angiology, Medical University of Brandenburg, Brandenburg, Germany. ${ }^{9}$ Kinderkrankenhaus auf der Bult, Diabeteszentrum für Kinder und Jugendliche, Hannover, Germany. ${ }^{10}$ Universitätsklinikum Freiburg, Medizinische Fakultät, Freiburg, Germany.

Received: 7 February 2020 Accepted: 15 July 2020

Published online: 29 July 2020

\section{References}

1. Chronic Kidney Disease Prognosis C, Matsushita K, van der Velde M, Astor BC, Woodward M, Levey AS, de Jong PE, Coresh J, Gansevoort RT. Association of estimated glomerular filtration rate and albuminuria with allcause and cardiovascular mortality in general population cohorts: a collaborative meta-analysis. Lancet. 2010;375(9731):2073-81.

2. Bramlage $P$, Lanzinger $S$, van Mark G, Hess E, Fahrner S, Heyer CHJ, Friebe M, Seufert J, Danne T, Holl RW. Patient and disease characteristics of type-2 diabetes patients with or without chronic kidney disease: an analysis of the German DPV and DIVE databases. Cardiovasc Diabetol. 2019;18(1):33.

3. Levey AS, Eckardt KU, Dorman NM, Christiansen SL, Hoorn EJ, Ingelfinger JR, Inker LA, Levin A, Mehrotra R, Palevsky PM, Perazella MA, Tong A, Allison SJ, Bockenhauer D, Briggs JP, Bromberg JS, Davenport A, Feldman HI, Fouque D, Gansevoort RT, Gill JS, Greene EL, Hemmelgarn BR, Kretzler M, Lambie M, Lane PH, Laycock J, Leventhal SE, Mittelman M, Morrissey P, Ostermann M, Rees L, Ronco P, Schaefer F, St Clair Russell J, Vinck C, Walsh SB, Weiner DE, Cheung M, Jadoul M, Winkelmayer WC. Nomenclature for kidney function and disease: report of a Kidney Disease: Improving Global Outcomes (KDIGO) Consensus Conference. Kidney Int. 2020;97(6):1117-29.

4. Gregg EW, Li Y, Wang J, Burrows NR, Ali MK, Rolka D, Williams DE, Geiss L. Changes in diabetes-related complications in the United States, 1990-2010. N Engl J Med. 2014;370(16):1514-23.

5. Narres M, Claessen H, Kvitkina T, Koch M, Rump LC, Weinreich T, Icks A. Incidence and relative risk of renal replacement therapy in people with and without diabetes between 2002 and 2016 in a German region. Diabetologia. 2020;63(3):648-58.

6. Colombo M, McGurnaghan SJ, Bell S, MacKenzie F, Patrick AW, Petrie JR, McKnight JA, MacRury S, Traynor J, Metcalfe W, McKeigue PM, Colhoun HM, Scottish Diabetes research network type 1 bioresource I, the Scottish renal R. Predicting renal disease progression in a large contemporary cohort with type 1 diabetes mellitus. Diabetologia. 2020;63(3):636-47.

7. Danne T, Kaltheuner M, Koch A, Ernst S, Rathmann W, Russmann HJ, Bramlage P, Studiengruppe D. "Dlabetes Versorgungs-evaluation" (DIVE)--a national quality assurance initiative at physicians providing care for patients with diabetes. Dtsch Med Wochenschr. 2013;138(18):934-9.

8. Bohn B, Schofl C, Zimmer V, Hummel M, Heise N, Siegel E, Karges W, Riedl M, Holl RW, initiative DPV. Achievement of treatment goals for secondary prevention of myocardial infarction or stroke in 29,325 patients with type 2 diabetes: a German/Austrian DPV-multicenter analysis. Cardiovasc Diabetol. 2016;15(1):72.

9. Schwab KO, Doerfer J, Hungele A, Scheuing N, Krebs A, Dost A, Rohrer TR, Hofer S, Holl RW. Non-high-density lipoprotein cholesterol in children with Diabetes: proposed treatment recommendations based on glycemic control, body mass index, age, sex, and generally accepted cut points. J Pediatr. 2015;167(6):1436-9.

10. Bramlage P, Lanzinger S, Rathmann W, Gillessen A, Scheper N, Schmid SM, Kaltheuner M, Seufert J, Danne T, Holl RW. Dyslipidaemia and its treatment in patients with type 2 diabetes: a joint analysis of the German DIVE and DPV registries. Diabetes Obes Metab. 2017;19(1):61-9.

11. Schwandt A, Denkinger M, Fasching P, Pfeifer M, Wagner C, Weiland J, Zeyfang A, Holl RW. Comparison of MDRD, CKD-EPI, and Cockcroft-Gault equation in relation to measured glomerular filtration rate among a large cohort with diabetes. J Diabetes Complicat. 2017;31(9):1376-83.

12. Levey AS, de Jong PE, Coresh J, El Nahas M, Astor BC, Matsushita K, Gansevoort RT, Kasiske BL, Eckardt KU. The definition, classification, and prognosis of chronic kidney disease: a KDIGO controversies conference report. Kidney Int. 2011;80(1):17-28.

13. KDIGO 2012. Clinical practice guideline for the evaluation and Management of Chronic Kidney Disease: chapter 1: definition and classification of CKD. Kidney Int Suppl. 2013;3:19-62.

14. Catapano AL, Graham I, De Backer G, Wiklund O, Chapman MJ, Drexel H, Hoes AW, Jennings CS, Landmesser U, Pedersen TR, Reiner Z, Riccardi G, Taskinen MR, Tokgozoglu L, Verschuren WMM, Vlachopoulos C, Wood DA, Zamorano JL, Cooney MT, Group ESCSD. 2016 ESC/EAS guidelines for the Management of Dyslipidaemias. Eur Heart J. 2016;37(39):2999-3058.

15. Gonzalez-Perez A, Saez ME, Vizcaya D, Lind M, Rodriguez LAG. Impact of chronic kidney disease definition on assessment of its incidence and risk factors in patients with newly diagnosed type 1 and type 2 diabetes in the UK: a cohort study using primary care data from the United Kingdom. Prim Care Diabetes. 2019;14(4):381-87.

16. Zelnick LR, Weiss NS, Kestenbaum BR, Robinson-Cohen C, Heagerty PJ, Tuttle K, Hall YN, Hirsch IB, de Boer IH. Diabetes and CKD in the United States population, 2009-2014. Clin J Am Soc Nephrol. 2017;12(12):1984-90.

17. Thomas MC, Cooper ME, Zimmet P. Changing epidemiology of type 2 diabetes mellitus and associated chronic kidney disease. Nat Rev Nephrol. 2016;12(2):73-81.

18. Warren B, Rebholz CM, Sang Y, Lee AK, Coresh J, Selvin E, Grams ME. Diabetes and trajectories of estimated glomerular filtration rate: a prospective cohort analysis of the atherosclerosis risk in communities study. Diabetes Care. 2018;41(8):1646-53.

19. Li L, Astor BC, Lewis J, Hu B, Appel LJ, Lipkowitz MS, Toto RD, Wang X, Wright JT Jr, Greene TH. Longitudinal progression trajectory of GFR among patients with CKD. Am J Kidney Dis. 2012;59(4):504-12.

20. Weldegiorgis M, de Zeeuw D, Li L, Parving HH, Hou FF, Remuzzi G, Greene T, Heerspink HJL. Longitudinal estimated GFR trajectories in patients with and without type 2 Diabetes and nephropathy. Am J Kidney Dis. 2018;71(1): 91-101.

21. Sikaneta $T$, Abdolell M, Taskapan H, Roscoe J, Fung J, Nagai G, Ting RH, Ng P, Wu G, Oreopoulos D, Tam PY. Variability in CKD stage in outpatients followed in two large renal clinics. Int Urol Nephrol. 2012;44(5):1461-6.

22. Xie Y, Bowe B, Xian H, Balasubramanian S, Al-Aly Z. Renal function trajectories in patients with prior improved eGFR slopes and risk of death. PLoS One. 2016;11(2):e0149283.

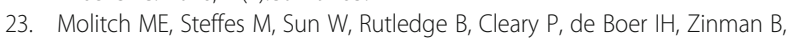
Lachin J, Epidemiology of Diabetes I, complications study G. Development and progression of renal insufficiency with and without albuminuria in adults with type 1 diabetes in the diabetes control and complications trial and the epidemiology of diabetes interventions and complications study. Diabetes Care. 2010;33(7):1536-43.

24. National Kidney Foundation. K/DOQI clinical practice guidelines for chronic kidney disease: evaluation, classification, and stratification. Am J Kidney Dis. 2002;39(2 Suppl 1):S1-266.

25. Vistisen D, Andersen GS, Hulman A, Persson F, Rossing P, Jorgensen ME. Progressive Decline in Estimated Glomerular Filtration Rate in Patients With 
Diabetes After Moderate Loss in Kidney Function-Even Without Albuminuria. Diabetes Care. 2019:42(10):1886-94.

26. Heerspink HJL, Greene T, Tighiouart H, Gansevoort RT, Coresh J, Simon AL, Chan TM, Hou FF, Lewis JB, Locatelli F, Praga M, Schena FP, Levey AS, Inker LA. Chronic kidney disease epidemiology C: change in albuminuria as a surrogate endpoint for progression of kidney disease: a meta-analysis of treatment effects in randomised clinical trials. Lancet Diabetes Endocrinol. 2019;7(2):128-39.

27. Coresh J, HJL H, Sang Y, Matsushita K, Arnlov J, Astor BC, Black C, Brunskill NJ, Carrero JJ, Feldman HI, Fox CS, Inker LA, Ishani A, Ito S, Jassal S, Konta T, Polkinghorne K, Romundstad S, Solbu MD, Stempniewicz N, Stengel B, Tonelli M, Umesawa M, Waikar SS, Wen CP, JFM W, Woodward M, Grams ME, Kovesdy CP, Levey AS, Gansevoort RT, Chronic Kidney Disease Prognosis C, Chronic Kidney Disease Epidemiology C. Change in albuminuria and subsequent risk of end-stage kidney disease: an individual participant-level consortium meta-analysis of observational studies. Lancet Diabetes Endocrinol. 2019:7(2):115-27.

28. Yu Z, Rebholz CM, Wong E, Chen Y, Matsushita K, Coresh J, Grams ME. Association between hypertension and kidney function decline: the atherosclerosis risk in communities (ARIC) study. Am J Kidney Dis. 2019; 74(3):310-9.

29. Tozawa M, Iseki K, Iseki C, Oshiro S, Ikemiya Y, Takishita S. Triglyceride, but not total cholesterol or low-density lipoprotein cholesterol levels, predict development of proteinuria. Kidney Int. 2002;62(5):1743-9.

30. Cholesterol Treatment Trialists C, Herrington WG, Emberson J, Mihaylova B, Blackwell L, Reith C, Solbu MD, Mark PB, Fellstrom B, Jardine AG, Wanner C, Holdaas H, Fulcher J, Haynes R, Landray MJ, Keech A, Simes J, Collins R, Baigent $C$. Impact of renal function on the effects of $L D L$ cholesterol lowering with statin-based regimens: a meta-analysis of individual participant data from 28 randomised trials. Lancet Diabetes Endocrinol. 2016;4(10):829-39.

31. American Diabetes A. 4. Comprehensive medical evaluation and assessment of comorbidities: standards of medical Care in Diabetes-2020. Diabetes Care. 2020;43(Suppl 1):S37-47.

32. Cosentino F, Grant PJ, Aboyans V, Bailey CJ, Ceriello A, Delgado V, Federici M, Filippatos G, Grobbee DE, Hansen TB, Huikuri HV, Johansson I, Juni P, Lettino M, Marx N, Mellbin LG, Ostgren CJ, Rocca B, Roffi M, Sattar N, Seferovic PM, Sousa-Uva M, Valensi P, Wheeler DC, Group ESCSD. 2019 ESC guidelines on diabetes, pre-diabetes, and cardiovascular diseases developed in collaboration with the EASD. Eur Heart J. 2020;41(2):255-323.

33. Nephrology ASo: ASN emphasized need for early detection of kidney disease, a silent killer [press release]. Available at https:/www.asn-online. org/news/2013/ASN_COMM_ACP_Screening_Response_102213_R12.pdf. Accessed 5 Feb 2020.

34. Saunders MR, Cifu A, Vela M. Screening for chronic kidney disease. JAMA. 2015;314(6):615-6.

35. National Kidney Foundation, Renal Physicians Association: National Kidney Foundation, Renal Physicians Association Urge Screening for those at Risk for Kidney Disease; 2013. Available at https://www.kidney.org/news/ newsroom/nr/NKF-RPA-Urge-Screening-for-atRisk-KD. Accessed 5 Feb 2020.

36. Radhakrishnan J, Remuzzi G, Saran R, Williams DE, Rios-Burrows N, Powe N, Team C-CS, Bruck K, Wanner C, Stel VS, European CKDBC, Venuthurupalli SK, Hoy WE, Healy HG, Salisbury A, Fassett RG, group CQ, O'Donoghue D, Roderick P, Matsuo S, Hishida A, Imai E, limuro S. Taming the chronic kidney disease epidemic: a global view of surveillance efforts. Kidney Int. 2014;86(2): 246-50

37. Bello AK, Ronksley PE, Tangri N, Singer A, Grill A, Nitsch D, Queenan JA, Lindeman C, Soos B, Freiheit E, Tuot D, Mangin D, Drummond N. A national surveillance project on chronic kidney disease management in Canadian primary care: a study protocol. BMJ Open. 2017;7(8):e016267.

38. Bello AK, Levin A, Tonelli M, Okpechi IG, Feehally J, Harris D, Jindal K, Salako BL, Rateb A, Osman MA, Qarni B, Saad S, Lunney M, Wiebe N, Ye F, Johnson DW. Assessment of global kidney health care status. JAMA. 2017;317(18): 1864-81.

39. Harnett $\mathrm{P}$, Jones M, Almond M, Ballasubramaniam G, Kunnath V. A virtual clinic to improve long-term outcomes in chronic kidney disease. Clin Med (Lond). 2018;18(5):356-63.

\section{Publisher's Note}

Springer Nature remains neutral with regard to jurisdictional claims in published maps and institutional affiliations.

Ready to submit your research? Choose BMC and benefit from:

- fast, convenient online submission

- thorough peer review by experienced researchers in your field

- rapid publication on acceptance

- support for research data, including large and complex data types

- gold Open Access which fosters wider collaboration and increased citations

- maximum visibility for your research: over $100 \mathrm{M}$ website views per year

At BMC, research is always in progress.

Learn more biomedcentral.com/submissions 